\title{
Knowledge of Mothers Regarding Home Care of Children undergone Cardiac Surgery with a View to Develop an Information Booklet
}

\author{
Poudel Pramila*1, Malla Chandni ${ }^{1}$ \\ ${ }^{1}$ Department of Nursing, National Medical College and Teaching Hospital, Birgunj, Nepal
}

\section{ABSTRACT}

Background: Children in developing countries are now receiving surgical repair for congenital heart defects. Despite advancement in the medical and surgical field, in developing countries where we have severe budgetary constraints, lack of funding for maintenance, poverty, skilled manpower deficit and knowledge deficit among public, pediatric cardiac surgery still remains a major challenge. For the parents of those children undergone corrective surgery more in-depth educational sessions are required to enable them to recognize and anticipate the complications so as to manage their child effectively at home following discharge. The study aims to assess the knowledge regarding home care of children undergone cardiac surgery with a view to develop an information booklet in home care.

Methods: A descriptive cross-sectional study was conducted among 60 mothers of children undergone cardiac surgery at a tertiary level cardiac center at Bengaluru, India using a structured knowledge questionnaire.

Results: Result revealed that majority $55 \%$ of the mothers had moderate knowledge, $40 \%$ had inadequate knowledge and only $5 \%$ had adequate knowledge. Variables such as age, education, occupation of mothers and source of information were significantly associated $(p<0.05)$ with the level of knowledge.
Conclusions: The knowledge of mothers regarding home care of children undergone cardiac surgery was found to be insufficient to enable them to take care of their children. The inadequate knowledge can be effectively strengthened through information booklet, discharge teaching and other mass media used as a source of information in educating not only the mothers of children but also other family members who acts as a care taker.

Keywords: cardiac surgery; home care; knowledge.

*Corresponding Author: Ms. Pramila Poudel Department of Nursing, National medical College and Teaching hospital, Birgunj, Parsa, Nepal, Email: pdlpramila123@yahoo.com

\section{INTRODUCTION}

Congenital cardiovascular defects, also known as congenital heart defects (CHD), "are structural problems that arise from abnormal formation of the heart or major blood vessels". ${ }^{1}$ According to the report on behalf of the American Heart Association and Strokes Statistics Subcommittee, in United states the incidence of congenital heart defects ranged between 4 and 10 per 1000 live births while it is 6.9 per 1000 live births in Europe and 9.3 per 1000 live births in Asia. ${ }^{1}$ Globally, the incidence of congenital heart disease is 8 to 12 per 1000 live births. ${ }^{2}$ 
Congenital heart defects are considered a tangible burden globally that influence mortality and morbidity. However, supporting data are sparse. Available data suggests that resources required for quality service are underestimated. Thus, it is suggested to develop cost effective intervention strategy to avoid premature mortality and permanent disabilities. ${ }^{3}$

According the data of 2013, the mortality associated with the congenital cardiovascular defects was $3,051 .^{1}$

The most common type of heart defect is a ventricular septal defect (VSD). It was studied that out of total CHD cases, about $25 \%$ of babies have a critical CHD. Infants with critical CHDs generally need surgery or other procedures in their first year of life. ${ }^{4}$

Despite advancement in the medical and surgical field, in developing countries where we have severe budgetary constraints, lack of funding for maintenance, poverty, skilled manpower deficit and knowledge deficit among public pediatric cardiac surgery still remains a major challenge. Nutrition, affordability and accessibility, fluctuating economic status are the major factors that are negatively influencing the outcome as compared to those of developed countries. ${ }^{5}$

Parents experience a mixture of shock, denial, fear, anger and an intense sense of sadness for an instance their infant is diagnosed with congenital heart defect. In spite of these emotions they must learn to be competent on providing care to meet their child's special needs. Care of the wound, nutrition, safe administration of prescribed medications, exercise and activity, detection of early complications remains the aspects that are required for the parents to learn about. Written reference material in the form of informational booklet, pamphlets and a family discharge teaching can be provided to the family and care provider at the time of discharge to deliver quality care at home following discharge. ${ }^{6}$ It is possible for the children to effectively recover and to live at home if home care is delivered carefully. ${ }^{7}$

Parental stress and anxiety is related to their child's health and welfare, economic hurdles and lack of family support. Parental knowledge on management of pain, fever, nutrition, activity, signs of early complications is of utmost importance and a better understanding to seek a doctor or taking child to hospital, which can reduce the economic burden as well. ${ }^{8}$

Based on a study findings the need to educate mother regarding care of infants at home following the cardiac surgery was very distinct. ${ }^{9}$ Many studies have concluded that one of the important factors influencing a better outcome in pediatric patients who underwent cardiac surgery is the provision of proper home care. ${ }^{10}$ More than the cardiologist think is adequate, education regarding the child care at home should be provided to parents of children undergone cardiac surgery. ${ }^{9}$

There is dearth of evidence that assessed the knowledge of mothers regarding home care of children who undergo cardiac surgery. This study was therefore conducted with the main aim to assess the knowledge of mothers regarding home care of children who underwent cardiac surgery.

\section{MATERIALS AND METHODS}

A descriptive cross sectional design was employed for the study. Data was collected from sixty $(n=60)$ mothers whose children underwent cardiac surgery at a tertiary level cardiac center at Bengaluru using a convenient sampling method. A pretested structured knowledge questionnaire was used to collect data after the ethical consideration from the institutional review committee. The internal consistency of instrument was computed by Karl Pearson coefficient correlation method and the reliability coefficient value of 0.83 was obtained. In addition, the stability of the tool was assessed by test retest method applying Spearman Brown prophecy formula. The tool was found to be stable as the value obtained for knowledge was $\mathrm{r}^{\prime}=0.88$.

Questionnaire consisted of 32 items (8 items consisting of general concept regarding CHD and 24 items consisting knowledge on home care aspects such as: activity needs of children, activities to perform and avoid by children, dietary pattern to be followed, symptoms of wound infection, methods of wound care, signs of complications, follow up process and when to 
refer doctor) have been selected. Each question carried one (1) score for the correct answer and zero $(0)$ score for the wrong answer which yielded a total score of 32. Knowledge level of respondents was classified as: Adequate knowledge, if score is $>75 \%$ of total score; moderately adequate knowledge, if score is $50-75 \%$ of total Score and inadequate knowledge, if score is $<50 \%$ of total Score. Data entry was done via SPSS version 16. Analysis was done using the descriptive statistics (percentage, mean scores) while Chi square test was done to assess the association between the knowledge of mothers and independent variables.

\section{RESULTS}

Table 1 : Distribution of mothers according to demographic characteristics.

\begin{tabular}{|c|c|c|}
\hline Variables & \multirow{2}{*}{ Frequency } & \multirow{2}{*}{ Percentage } \\
\hline Age in years & & \\
\hline $20-30$ years & 26 & 43.3 \\
\hline $30-40$ years & 25 & 41.7 \\
\hline 40 years and above & 9 & 15.0 \\
\hline Religion & Frequency & Percentage \\
\hline Hindu & 38 & 63.3 \\
\hline Christian & 10 & 16.7 \\
\hline Muslim & 12 & 20.0 \\
\hline Type of Marriage & Frequency & Percentage \\
\hline Consanguineous & 20 & 33.3 \\
\hline Non Consanguineous & 40 & 66.7 \\
\hline Educational Level & Frequency & Percentage \\
\hline Primary school & 2 & 3.3 \\
\hline Secondary education & 15 & 25.0 \\
\hline Intermediate level & 25 & 41.7 \\
\hline Graduation and above & 18 & 30.0 \\
\hline Occupation & Frequency & Percentage \\
\hline Government employee & 15 & 25.0 \\
\hline Private employee & 25 & 41.7 \\
\hline Skilled worker & 14 & 23.3 \\
\hline Self employed & 6 & 10.0 \\
\hline Family type & Frequency & Percentage \\
\hline Nuclear Family & 55 & 91.7 \\
\hline Joint Family & 5 & 8.3 \\
\hline Family history of congenital heart disease & Frequency & Percentage \\
\hline No & 54 & 90.0 \\
\hline Yes & 6 & 10.0 \\
\hline Source of information & Frequency & Percentage \\
\hline No Information & 10 & 16.7 \\
\hline Printed media & 11 & 18.3 \\
\hline Electronic media & 20 & 33.3 \\
\hline Health Personnel & 17 & 28.3 \\
\hline Family members/ relatives & 2 & 3.3 \\
\hline
\end{tabular}

\section{Table 2: Overall knowledge scores of the mothers.}

\begin{tabular}{|l|l|}
\hline Knowledge level & $\mathrm{n}(\%)$ \\
\hline Inadequate knowledge & $24(40.0)$ \\
\hline Moderate knowledge & $33(55.0)$ \\
\hline Adequate knowledge & $3(5.0)$ \\
\hline Total & $\mathbf{6 0}(\mathbf{1 0 0 . 0})$ \\
\hline
\end{tabular}


Table 3 : Area wise analysis of knowledge scores of mothers.

$\mathrm{n}=60$

\begin{tabular}{|l|c|c|c|c|c|c|}
\hline Knowledge aspects & $\begin{array}{c}\text { Number of } \\
\text { Items }\end{array}$ & $\begin{array}{c}\text { Maximum } \\
\text { Score }\end{array}$ & Mean & Mean \% & Median & SD \\
\hline $\begin{array}{l}\text { General concept regarding } \\
\text { Congenital Heart Disease }\end{array}$ & 8 & 8 & 4.65 & 58.12 & 5 & 1.424 \\
\hline Knowledge on home care & 24 & 24 & 12.95 & 53.95 & 12.5 & 2.521 \\
\hline Overall & $\mathbf{3 2}$ & $\mathbf{3 2}$ & $\mathbf{1 7 . 6 0}$ & $\mathbf{5 5}$ & $\mathbf{1 7}$ & $\mathbf{3 . 1 6 9}$ \\
\hline
\end{tabular}

Table 4 : Association of knowledge score of mothers with the demographic variables.

\begin{tabular}{|c|c|c|c|c|c|}
\hline Variables & Bolow Modian & Modian and abovo & |Chi s numant | & $\mathbf{n f}$ & D value \\
\hline 1. Age in years & Delow inediant & Median and above & |Cint squáre & DI & Palue \\
\hline a. 20-30 years & 14 & 12 & \multirow{3}{*}{7.151} & \multirow{3}{*}{2} & \multirow{3}{*}{$0.028^{*}$} \\
\hline b. $30-40$ years & 5 & 20 & & & \\
\hline c. 40 years and above & 5 & 4 & & & \\
\hline 2. Religion & Below Median & Median and above & Chi square & Df & P value \\
\hline a. Hindu & 17 & 21 & \multirow{3}{*}{3.494} & \multirow{3}{*}{2} & \multirow{3}{*}{0.174} \\
\hline b. Christian & 5 & 5 & & & \\
\hline c. Muslim & 2 & 10 & & & \\
\hline 3. Type of Marriage & Below Median & Median and above & Chi square & Df & P value \\
\hline a. Consanguineous & 9 & 11 & \multirow{2}{*}{0.313} & \multirow{2}{*}{1} & \multirow{2}{*}{0.576} \\
\hline b. non Consanguineous & 15 & 25 & & & \\
\hline 4. Education & Below Median & Median and above & Chi square & Df & P value \\
\hline primary school & 1 & 1 & \multirow{4}{*}{14.833} & \multirow{4}{*}{3} & \multirow{4}{*}{$0.002 *$} \\
\hline secondary education & 12 & 3 & & & \\
\hline Pre University College & 8 & 17 & & & \\
\hline Graduation and above & 3 & 15 & & & \\
\hline 5. Occupation & Below Median & Median and above & Chi square & Df & P value \\
\hline a. $\quad$ Government employee & 9 & 6 & \multirow{4}{*}{8.492} & \multirow{4}{*}{3} & \multirow{4}{*}{$0.037 *$} \\
\hline Private employee & 5 & 20 & & & \\
\hline Skilled worker & 8 & 6 & & & \\
\hline Self employed & 2 & 4 & & & \\
\hline 6. Family type & Below Median & Median and above & Chi square & Df & P value \\
\hline Nuclear Family & 24 & 31 & \multirow{2}{*}{3.636} & \multirow{2}{*}{1} & \multirow{2}{*}{0.057} \\
\hline Joint Family & 0 & 5 & & & \\
\hline 7. Family history & Below Median & Median and above & Chi square & Df & Pvalue \\
\hline No & 22 & 32 & \multirow[b]{2}{*}{0.123} & \multirow[b]{2}{*}{1} & \multirow[b]{2}{*}{0.725} \\
\hline Yes. & 2 & 4 & & & \\
\hline 8. Source of information & Below Median & Median and above & Chi square & Df & P value \\
\hline a. $\quad$ No Information & 9 & 1 & \multirow{5}{*}{13.230} & \multirow{5}{*}{4} & \multirow{5}{*}{$0.01 *$} \\
\hline b. $\quad$ Printed media & 4 & 7 & & & \\
\hline Electronic media & 5 & 15 & & & \\
\hline Health Personnel & 5 & 12 & & & \\
\hline Family members/ relatives & 1 & 1 & & & \\
\hline
\end{tabular}

$* \mathrm{p}$ value significant at $<0.05$

The Chi square test done to assess the association of knowledge level of respondents and independent variables showed that knowledge level of respondents was found to be statistically associated with age $(\mathrm{p}=0.028)$, education level $(\mathrm{p}=0.002)$, occupation $(\mathrm{p}=0.037)$ and sources of information (0.001) (Table 4).

Therefore, the hypothesis stated as there will be significant association between knowledge level and their selected variables is accepted.

\section{DISCUSSION}

Congenital abnormalities are found to be one of the main causes of heart disease in children. Chronic illness like congenital heart disease (CHD) must be understood precisely by parents and their families. Following the treatment regimen within improved emotional state; parental awareness regarding the nature of their children with $\mathrm{CHD}$, its treatment and complications is expected to reflect on parent's practices related to nutrition, growth and development of their children. Several 
recent studies have depicted that understanding of illness, treatment and the complications by children, adolescents, and caretakers with CHD does not remain satisfactory. ${ }^{11}$

The present study was conducted to assess the knowledge of mothers regarding home care of children undergone cardiac surgery with a view to develop an informational booklet on home care. Total participants were 60 mothers of those children who underwent cardiac surgery. Among them Majority 55\% of the mothers had moderately adequate knowledge, $40 \%$ had inadequate knowledge and remaining $5 \%$ of them had adequate knowledge.

This finding is supported by a retrospective study which was conducted to review the knowledge of mothers regarding care of children undergone cardiac surgery at a tertiary care referral center. This finding is similar to the finding of present study concluding that the mothers have inadequate knowledge on home care of children undergone surgery thus focusing upon the importance of proper home care management especially wound hygiene and general hygiene of the children. ${ }^{12}$

A comparative study conducted at Hospital for Sick Children, Toronto, Ontario to examine the knowledge of mothers whose infants had cardiac surgery. The results supported the use of standardized teaching and community followup for mothers charged with caring for children who are recuperating from cardiac surgery as the mothers reported the need of information is "extremely important" for them to know regarding the care of their children following cardiac surgery. ${ }^{9}$

According to a study, parents should be supported, educated, communicated and co-ordinated properly in order to make them competent in taking care of their children properly at home following cardiac surgery. ${ }^{13}$

A study was conducted in UK to assess the perceived needs of the parents of children with congenital heart disease and to determine the support and services that the families were currently receiving concluded that interventions need to be targeted so that those parents needing additional services and support. Thus, better care can be delivered to those children with CHD at home. $^{14}$

\section{CONCLUSION}

This study was conducted to assess the knowledge on home care of children undergone cardiac surgery among the mother. The knowledge of mothers regarding home care of children undergone cardiac surgery was found to be inadequate. The inadequate knowledge can be effectively strengthened through information booklet, discharge teaching and other mass medias used as a source of information in educating not only the mothers of children but also other family members who acts as a care taker.

\section{ACKNOWLEDGEMENTS}

Authors are thankful to the Department of Child health Nursing of Acharya College of Nursing, for their support and guidance during the course of the study. Sincere thanks to the participants of the study without whom the study would not have been possible.

\section{REFERENCES}

1. Mozaffarian D, Benjamin EJ, Go AS, et al. American Heart Association Statistics update: a report from the American Heart Association. Circulation. 2016; 133 (4) : 338-60

2. Hoffman J. Incidence of congenital heart disease.I. Postnatal incidence. Pediatr Cardiol. 2007; 16(3):103-13.

3. Nicole A. S, Doruk O, Peter D, Diana L. F. Congenital Anomalies in Low- and MiddleIncome Countries: The Unborn Child of Global Surgery. World J Surg. 2015; 39:3640.

4. American Heart Association - Congenital Cardiovascular Disease Statistics. Retrieved from http://www.americanheart.org.http:// www.congenitalheartdefects.com/stats. $\mathrm{html}$ on 2072-09-04.

5. Rao SG. Pediatric cardiac surgery in developing countries. Pediatr Cardiol. 2007; 28:144-8. 
6. Pye S, Green A. Parent education after newborn congenital heart surgery. Advances in Neonatal Care. 2003; 3(3):147-56.

7. Monteleone ME, Racette J. Affair of the heart. Pediatric cardiac homecare. 1993; 12(12):43-6.

8. Jacqui C, Stephen D. Managing childhood fever and pain - the comfort loop. Child Adolesc Psychiatry Ment Health. 2007; 1:7.

9. Stinson J, McKeever P. Mother's information needs related to caring for infants at home following cardiac surgery. J Pediatr Nurs. 1995; 10 (1):48-57.

10. Staveski SL, Parveen VP, Madathil SB, Kools S, Franck LS. Parent education discharge instruction program for care of children at home after cardiac surgery in Southern India. Cardiol young. 2015; 1-8.
11. Laila ME, Mohammed HS, Sulafa KM. Parental knowledge of their children's congenital heart disease and its impact on their growth. Khartoum Medical Journal. 2009; 02(02):191- 6.

12. Sohn AH, Schwartz JM. Risk factors and risk adjustment for surgical site infections in pediatric cardiothoracic surgery patients. Am J Infect Control. 2010; 38(9): 706-10.

13. Lerret SM. Discharge Readiness: An Integrative Review Focusing on Discharge Following Pediatric Hospitalization. JSPN. 2009; 14(4): 245-55.

14. Wray J, Maynard L. The needs of families of children with heart disease. J Dev Behav Pediatr. 2006; 27(1):11-7. 